\title{
Fault-Tolerant Operation of Power Converters in PHEVs Coupled by a Scott Transformer
}

\author{
MAI Tuan Dat ${ }^{\dagger}$, Yonghua CHENG* and Johan DRIESEN* ${ }^{* \dagger}$ \\ *Vlaamse Instelling voor Technologisch Onderzoek(VITO) \\ Boeretang 200 \\ B-2400 MOL, Belgium. \\ yonghua.cheng@vito.be \\ ${ }^{\dagger}$ K.U. Leuven, ESAT - ELECTA \\ Kasteelpark Arenberg 10, bus 2445 \\ 3001 HEVERLEE, Belgium. \\ tuandat.mai@esat.kuleuven.be; johan.driesen@esat.kuleuven.be
}

\begin{abstract}
PHEV are becoming more widespread, as they have more eco-friendly and more economical characteristics than conventional vehicles. A possible power converter is investigated to sustain the on-road operation of PHEV when one or more of the power switches is damaged. In this paper, a Scott transformer topology is presented to provide redundancy to the power switches in an Integrated Power Module (IPM). A fault-tolerant scheme is simulated to test the operation of a permanent-magnet synchronous machine (PMSM) in a PHEV.
\end{abstract}

Index Terms-Scott transformer, redundant components, faults, fault-tolerant, traction motor, reference frame, VSI.

\section{INTRODUCTION}

The Toyota Prius has kick started the electric vehicle (EVs), as well as the plug-in hybrid electrical vehicle (PHEV) market. The definition of "hybrid car" has become diversified later and, consequently, various standards emerged to improve the performance and the efficiency of EVs and PHEVs.

Permanent-magnet synchronous machines are gradually considered the better choice of traction motors, due to their high power density and high efficiency [1]. These machines, however, require power electronics to obtain a variable, mechanical speed.

The rapid development of power electronic devices for future EVs and PHEVs is challenged by higher requirements on reliability and energy conversion efficiency during operation. The key element of electrified vehicle systems are the electric power converters. Redundancy of the power switches is preferred to provide fault-tolerant operation, even under a fault condition [2].

In recent years, a great deal of research has been carriedout on the development of fault-tolerant AC motor electric drives [1]. For instance, in [3], fault compensation strategies for pulse-width modulated, voltage-source inverters (PWMVSI) used in motor drives are presented in order to provide compensation for open-circuit and short-circuit failures in the power converter devices. In addition, multiphase machines are employed under fault operating conditions, as described in [4],
[5]. The advantage of multiphase machines over three-phase machines is that the motor is still able to operate properly, even when a fault occurs in one or more phases, by involvement of the remaining, healthy phases [6].

However, existing approaches implement numerous, additional power switches for the DC boost and the inverter stages [7]. The proposed approach aims to reduce the number of additional switches, while enabling a fault-tolerant operating mode, by using a Scott transformer [8], [9] in the power converter system.

Conventional inverters employ three legs, constituting six power electronics switches, which are integrated in a commercial Integrated Power Electronics Module (IPM). The proposed approach employs a novel scheme where only two legs are in operation and the third leg is regarded as a redundant power component. When a converter fails due to a failure of one leg, the third leg is activated to restore the operation of the converter.

In this paper, the feasibility of this scheme is examined by studying and evaluating the performance of the system after a fault. For the fault-tolerant procedure, a particular approach to fault diagnostics is developed. This method ensures a higher reliability of the power torque of the traction motor in electric vehicles.

\section{Modeling}

\section{A. Component Design}

The proposed converter system constitutes 3 main parts: a energy storage consisting of 28 modules of $7.2 \mathrm{~V} \mathrm{NiMH}$ battery packs [10]); power electronic switches, including an IPM and auxiliary switches for fault restoration; a Scott transformer functioning as both a voltage booster and threephase output transformer.

The battery packet is modeled as energy storage system in a Toyota Prius hybrid electric vehicle. However, the power 
source is a bipolar DC with a potential of $V_{D C}=14 \times 7.2=$ $100.8 \mathrm{~V}$ for each pole .

In order to allow the motor to operate properly in faulted mode, and maintain the performance during normal operating conditions, a power electronic system consisting of six power switches in an IPM and two triacs is presented [2], [11], [12].

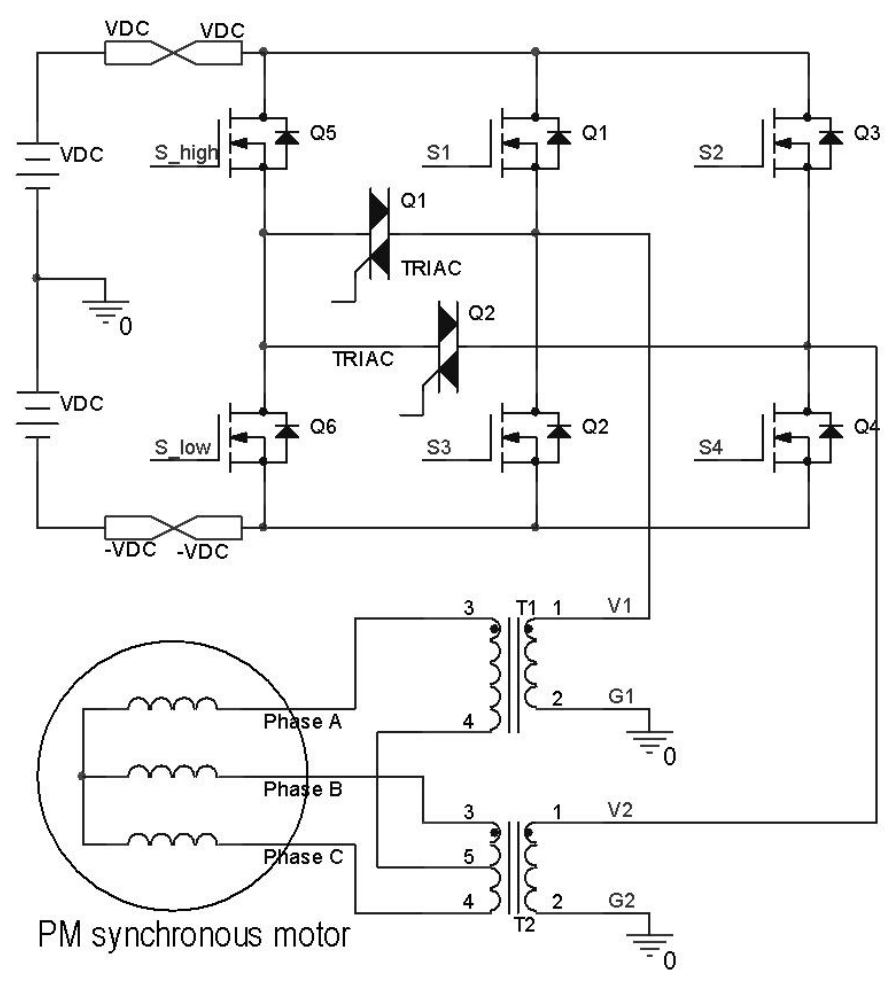

Fig. 1. The connection of switches in an IPM and triacs

Four switches in two legs are the active switching components during normal operation, while two switches in the remaining leg only operate as redundant components. These devices are used to replace the faulty leg in a fault-tolerant mode. Fig. 1 illustrates the power-electronic system modeled in the simulation.

This topology of redundant converters [2], [11], [12] is characterized by the presence of additional switching devices. Those switches are used as back-up units when one of the main legs is in failure. Beside additional switches, power flow controlling switches, such as triacs, are also implemented to direct energy into the faulted leg. Fig. 1 shows a detailed topology of the proposed redundant power converters in this paper. Compared to existing topologies, this approach requires fewer additional power-electronic devices.

The Scott transformer includes two separate transformers with a special connection, which is shown in Fig. 1. The structure of the Scott transformer in this paper is quite similar to the Scott transformers employed in high speed railway systems (HSR), illustrated in Fig. 2. However, in this application, the physical size of the transformer can be kept small, as it operates at the high switching frequency of the inverter.

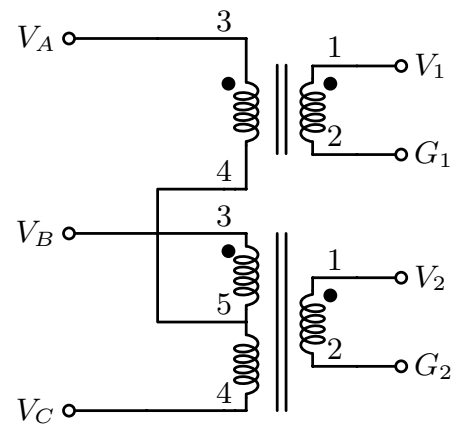

Fig. 2. The feeding transformer with Scott connection

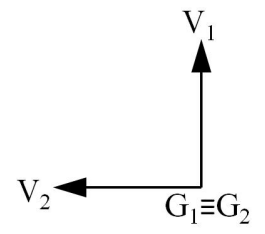

voltage phasor in primary

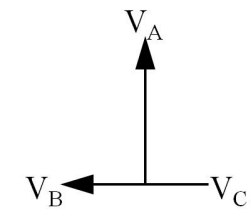

voltage phasor in secondary
Fig. 3. Voltage phasor with Scott connection

Two single coils are the primary side denoted by $V_{1}-G_{1}$ and $V_{2}-G_{2}$, while three-phase windings are at the secondary side denoted by $V_{A}, V_{B}, V_{C}$. The electrical voltage relationship between the primary and secondary side is given by a Clarke transformation, where $V_{A B}, V_{B C}, V_{C A}$ are line voltages in the secondary side of the Scott transformer. The inversion of Eq. 1 delivers an expression for the line voltages from $V_{1}$ and $V_{2}$ :

$$
\begin{gathered}
{\left[\begin{array}{l}
V_{1} \\
V_{2}
\end{array}\right]=\frac{2}{3} \cdot \frac{N_{1}}{N_{2}}\left[\begin{array}{ccc}
1 & -\frac{1}{2} & -\frac{1}{2} \\
0 & \frac{\sqrt{3}}{2} & -\frac{\sqrt{3}}{2}
\end{array}\right]\left[\begin{array}{l}
V_{A B} \\
V_{B C} \\
V_{C A}
\end{array}\right]} \\
{\left[\begin{array}{l}
V_{A B} \\
V_{B C} \\
V_{C A}
\end{array}\right]=\frac{2}{3} \cdot \frac{N_{1}}{N_{2}}\left[\begin{array}{cc}
1 & 0 \\
-\frac{1}{2} & \frac{\sqrt{3}}{2} \\
-\frac{1}{2} & \frac{\sqrt{3}}{2}
\end{array}\right]\left[\begin{array}{l}
V_{1} \\
V_{2}
\end{array}\right]}
\end{gathered}
$$

Hence, the magnitudes of $V_{A B}, V_{B C}, V_{C A}, V_{1}$ and $V_{2}$ are equal in case of sinusoidal waveforms. Neglecting the magnetization current, we get the following equation from the $\mathrm{mmf}$ equations:

$$
\begin{cases}N_{1} \cdot i_{1}+\frac{\sqrt{3}}{2} \cdot N_{2} \cdot i_{A} & =0 \\ N_{1} \cdot i_{2}+\frac{1}{2} \cdot N_{2} \cdot i_{B}-\frac{1}{2} \cdot N_{2} \cdot i_{C} & =0\end{cases}
$$

By applying Kirchhoff's current law:

$$
i_{A}+i_{B}+i_{C}=0
$$

Finally, the equation is derived that expresses the relation between the primary-side currents and the secondary-side 
TABLE I

SIMULATION PARAMETERS OF THE TRACTION MOTOR

\begin{tabular}{|c|c|c|}
\hline Parameter & Value & Unit \\
\hline Stator resistance Rs & 0.0079 & $\operatorname{Ohm}(\Omega)$ \\
d-axis stator inductance Ld & 0.00023 & $\operatorname{Henry}(H)$ \\
q-axis stator inductance Lq & 0.00056 & $\operatorname{Henry}(H)$ \\
Rotor flux & 0.3 & Weber $(W b)$ \\
Inertia J & 0.001 & $\mathrm{kg.m}$ \\
Pairs of poles P & 9 & - \\
\hline
\end{tabular}

currents:

$$
\left[\begin{array}{l}
i_{1} \\
i_{2}
\end{array}\right]=\frac{N_{2}}{N_{1}}\left[\begin{array}{ccc}
-\frac{\sqrt{3}}{2} & 0 & 0 \\
0 & -\frac{1}{2} & \frac{1}{2}
\end{array}\right]\left[\begin{array}{l}
i_{A} \\
i_{B} \\
i_{C}
\end{array}\right]
$$

or

$$
\left[\begin{array}{l}
i_{A} \\
i_{B} \\
i_{C}
\end{array}\right]=\frac{N_{1}}{N_{2}}\left[\begin{array}{cc}
-\frac{\sqrt{3}}{2} & 0 \\
\frac{1}{\sqrt{3}} & -1 \\
\frac{1}{\sqrt{3}} & 1
\end{array}\right]\left[\begin{array}{l}
i_{1} \\
i_{2}
\end{array}\right]
$$

Nevertheless, the core has to consist of a high-frequency magnetic material to deliver power from the source to the motor, as well as to ensure the required compactness in PHEVs.

The synchronous motor simulated in this paper has parameters listed in Table I.

\section{B. Fault Diagnostics and Suitable Control}

The most frequent faults of a single power-electronic switch are known as a shorted-circuit or a permanent open-circuit. The second type of fault appears more often, based on the probability of fault occurrences listed in [11]. On the other hand, short-circuited legs are rapidly isolated to both positive and negative voltage due to the blowing-out of fast fuses or the individual power-electronic devices themselves.

The fault detection scheme [2], [12] applied to power converters is as follows:

- Identify faulty leg.

- Deactivate the operation of faulty leg and prevent the short-circuit fault.

- Activate the redundant leg.

- Make a galvanic connection to the fault phase through triacs.

For automotive traction systems, electric currents are the main factors to produce electromotive torque. Accordingly, three Hall current sensors in the secondary side and one incremental encoder are employed to control the torque of the motor. They also occupy the role of detecting faults in the power converter. During normal operating conditions, a PI controller is implemented to generate the output reference current in the $\mathrm{d}-\mathrm{q}$ rotating reference frame, according to the deviation between the desired and the actual motor speed. The states of the switches in the power legs are controlled by hysteresis blocks, comparing the reference currents and measured currents in a static, orthogonal reference frame.

Output current in the static, orthogonal reference frame is defined by the Clarke transformation in Eq. 7.

$$
\left[\begin{array}{c}
i_{\alpha} \\
i_{\beta}
\end{array}\right]=\frac{2}{3}\left[\begin{array}{ccc}
1 & -\frac{1}{2} & -\frac{1}{2} \\
0 & \frac{\sqrt{3}}{2} & -\frac{\sqrt{3}}{2}
\end{array}\right]\left[\begin{array}{l}
i_{A} \\
i_{B} \\
i_{C}
\end{array}\right]
$$

In reality, the alpha-beta currents are taken into account to send feedback to the current-fed controller in this paper. When the power converter is in a healthy state, currents fed into the two primary-windings of the Scott transformer are balanced sinusoidal waveforms, and are either lagging or leading by $90^{\circ}$. Consequently, three balanced sinusoidal phase currents are produced at the secondary side, thanks to the connections and winding ratios of the Scott transformer. The magnitude of the output current vector is expressed by Eq. 8 .

$$
|\vec{i}|=\left|\frac{2}{3}\left(\overrightarrow{i_{A}}+\overrightarrow{i_{B}}+\overrightarrow{i_{C}}\right)\right|=\sqrt{i_{\alpha}{ }^{2}+i_{\beta}{ }^{2}}
$$

The reference currents for the power converter topology are generated by including a speed controller, such as a PI compensation block. When one of the two legs is in failure, the energy is not properly delivered to the secondary, hence the magnitude of measured vector current is smaller than the reference output current set by the PI controller.

$$
i_{\text {ref }}-i_{m e s} \geq \sigma>\text { hysteresis band gap }
$$

where $\sigma$ is the permissible error margin in the system.

When the condition of Eq. 8, 9 is satisfied, the fault-tolerant mode is activated to identify the faulted leg. However, to eliminate undesirable distortions [12], the fault detection scheme in Fig. 4 is implemented. The mechanism identifying the faulted

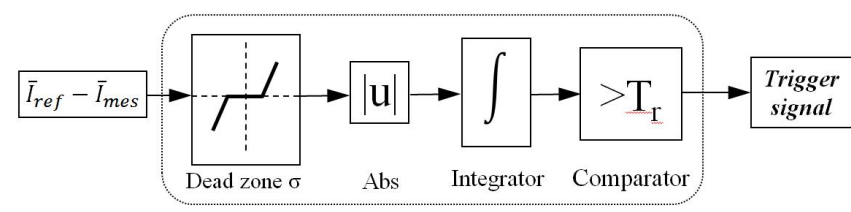

Fig. 4. Block diagram of the fault detection scheme of the current error

leg is also based on the error between the reference current value and the feedback current, taking into account the error margin. The error between the set-point value and the feedback value is expressed by Eq. 10 .

$$
\left\{\begin{array}{l}
\varepsilon_{1}=\left|i_{1 \text { ref }}-i_{1 \text { measure }}\right| \\
\varepsilon_{2}=\left|i_{2 \text { ref }}-i_{2 \text { measure }}\right|
\end{array}\right.
$$

When a fault in Leg $1\left(V_{1}-G_{1}\right)$ is assumed, there is no current flow through the secondary winding of the upper transformer $\mathrm{T} 1$, and only the current flowing through the bottom transformer $\mathrm{T} 2$ goes through the motor. Hence, the measured current in Leg 1 represented by $i_{\alpha}$ is lower than the reference value. Eq. 11 illustrates that $\varepsilon_{1}$ is higher than the 
limit value $\sigma$, while $\varepsilon_{2}$ is lower than the margin value in this case.

$$
\begin{gathered}
\left\{\begin{array}{l}
\varepsilon_{1}>\sigma \\
\varepsilon_{2}<\sigma
\end{array} \Longrightarrow \text { fault in Leg } 1\right.
\end{gathered}
$$

A similar mechanism of fault detection is also applied to Leg $2\left(V_{2}-G_{2}\right)$, which is expressed in Eq. 12.

$$
\begin{gathered}
\left\{\begin{array}{l}
\varepsilon_{1}<\sigma \\
\varepsilon_{2}>\sigma
\end{array} \Longrightarrow \text { fault in Leg } 2\right. \\
\Rightarrow\left\{\begin{array}{l}
\text { step } 1: \text { activate redundant leg } \\
\text { step } 2: \text { direct signal from Leg } 2 \text { to the redundant leg } \\
\text { step } 3: \text { activate triac } Q_{2}
\end{array}\right.
\end{gathered}
$$

Thanks to Eq. 11-12, a fault detection scheme is able to figureout which leg is in the failure state. Because the fault detection is mainly based on the output currents, it is rational that three current sensors are employed, one in each phase of the traction motor. The measured phase currents are: $i_{A}, i_{B}, i_{C}$. Therefore, the system is switched into the fault-tolerant mode and identifies the damaged leg, after a power-electronic failure, by sensing the zero-sequence current described in Eq. 8 .

\section{Simulation Results}

The simulation is carried-out to validate the functioning of the proposed topology. The first leg of the converter is set to be faulted at $t=4 \mathrm{~ms}$. This fault is sensed, and the redundant leg is activated. The system also measures fault values to choose the appropriate triac that will connect the redundant leg to the mid-point of the faulted leg. The fault is cleared at $t=5.2 \mathrm{~ms}$.

PLECS toolbox is chosen to simulate the power converter in the MATLAB-Simulink environment, while fault intervention, model reconfiguration and fault-tolerant control are modeled in Simulink. Simulation results are shown in Fig. 5 to Fig. 15, including phase currents in the secondary winding, rotor speed and electrical torque.

The converter in the simulation is a current-fed VSI, using a hysteresis control approach. The motor is starting-up from zero-speed to $600 \mathrm{rad} / \mathrm{s}$ with a mechanical torque of $10 \mathrm{Nm}$. The converter is initially in a healthy-state. At $t=4 \mathrm{~ms}$, Leg $1\left(Q_{1}, Q_{2}\right)$ is faulted and set to an open-circuit state. The fault-tolerant operation is executed at $t=5.2 \mathrm{~ms}$ to restore the three-phase sinusoidal currents feeding the traction motor. At $t=25 \mathrm{~ms}$, mechanical torque is increased to $40 \mathrm{Nm}$ and kept constant at that value.

Simulation results are illustrated in Fig. 5, showing how the fault condition is managed by the proposed topology in order to guarantee the output currents of the converter. Currents in phase $\mathrm{B}$ and $\mathrm{C}$ is symmetric in Fig. 5 when the fault occurs at Leg 1 . This can be explained by the wire connection topology of the Scott transformer: phases $\mathrm{B}$ and $\mathrm{C}$ share a common single transformer at two end terminals.

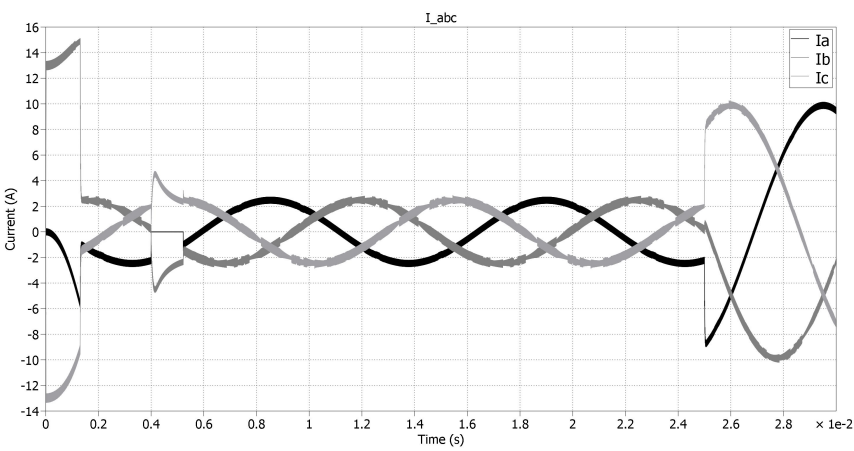

Fig. 5. Three-phase measured currents at the secondary side

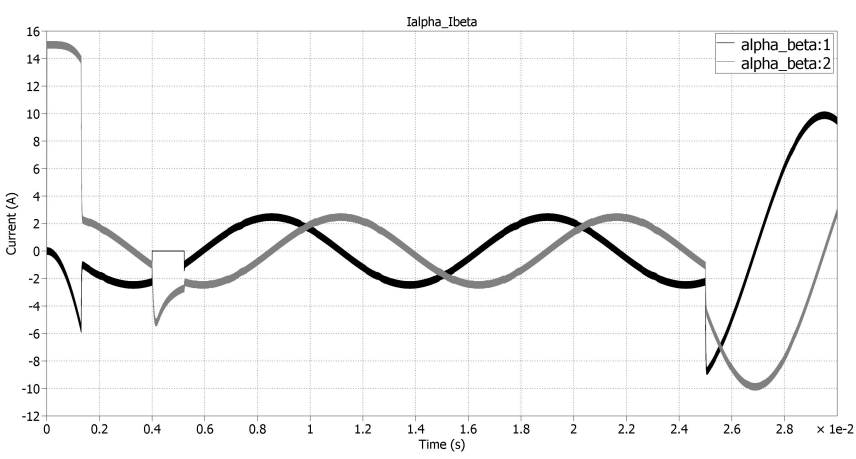

Fig. 6. Measured currents at the secondary side transformed into the static orthogonal reference frame

Fig. 6 illustrates the waveforms of the phase currents after applying the Clarke transformation. The two current components $i_{\alpha}$ and $i_{\beta}$ are orthogonal before and after fault. During fault at Leg $1, i_{\alpha}$ is constantly zero, corresponding to the zerovalue of current $i_{\alpha}$. The behavior of the output currents is explained by Eq. 7. A detail of the current waveforms is shown in Fig. 7.

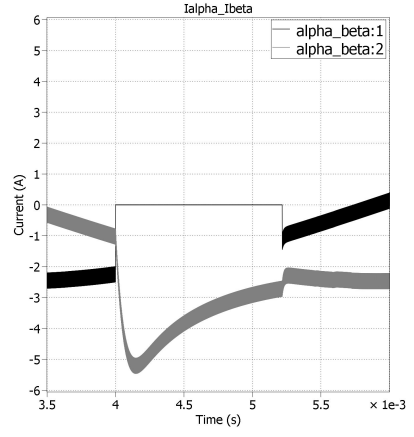

(a) $\alpha \beta$ orthogonal reference frame

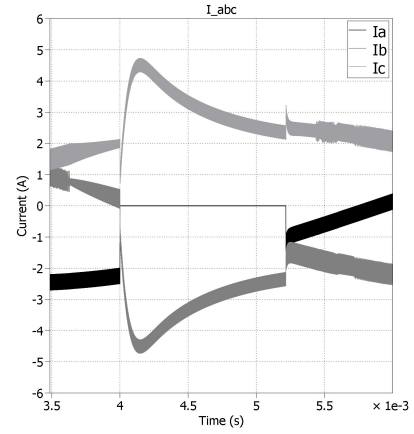

(b) abc reference frame
Fig. 7. Measured currents at the secondary side at the pre-fault point $t=4 \mathrm{~ms}$ and the post-fault point $t=5.2 \mathrm{~ms}$

Fig. 8 shows a decline in rotor speed during the fault. In fact, the speed drops to $596 \mathrm{rad} / \mathrm{s}$ at $t=4.12 \mathrm{~ms}$ and is restored before activating the fault-tolerant mode. This can be explained by the approximate alignment of the rotor flux between the current vectors of phase $\mathrm{B}$ and phase $\mathrm{C}$, which are healthy in this simulation. Therefore, the stator flux produced 
by $i_{B}$ and $i_{C}$ is powerful enough to speed-up the rotor shaft during fault. Another fault time is simulated at $t=2 \mathrm{~ms}$ in Fig. 12, which shows a worse case where the rotor speed is only restored to the reference speed after entering faulttolerant mode. The fault mode is terminated at $t=3.41 \mathrm{~ms}$, and the rotor speed is restored at $t=3.59 \mathrm{~ms}$. To reach

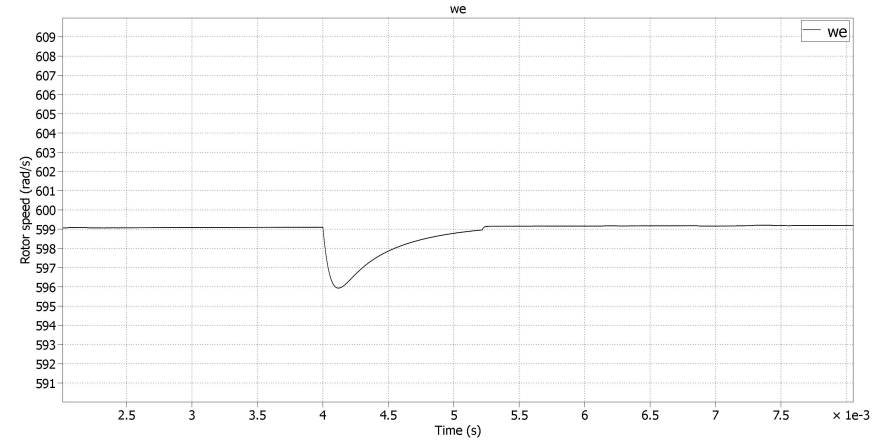

Fig. 8. Speed transient before and after fault occurs at $t=4 \mathrm{~ms}$

the reference speed as quickly as possible, controllability of the PI controller results in a step-change response of the electrical torque. During start-up, the electrical torque is held constant at the maximum value of $60 \mathrm{Nm}$. The current

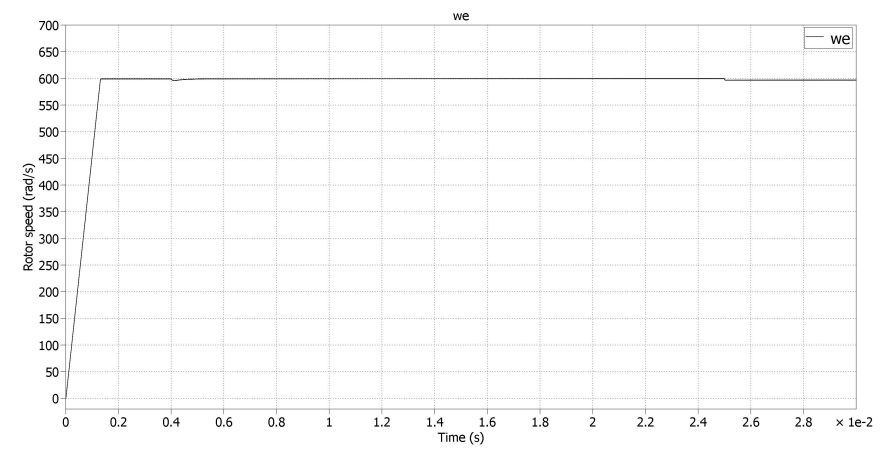

Fig. 9. Mechanical rotor speed of the traction motor in the simulation



Fig. 10. Electrical torque in the simulation

produced by the additional leg, conducted through the triac, is illustrated in Fig. 11. During healthy-state, there is no current conducted by the triacs. The relevant device is not turned-on until $t=5.2 \mathrm{~ms}$, when the fault-tolerant mode is triggered.
The current waveforms after fault remain sinusoidal and wellmatched with the operation of the electric drive to sustain the torque of the traction motor. The upper switch of the redundant leg Q5 is operated to supply the positive current, while the lower switch Q6 is operated to feed the negative current. A

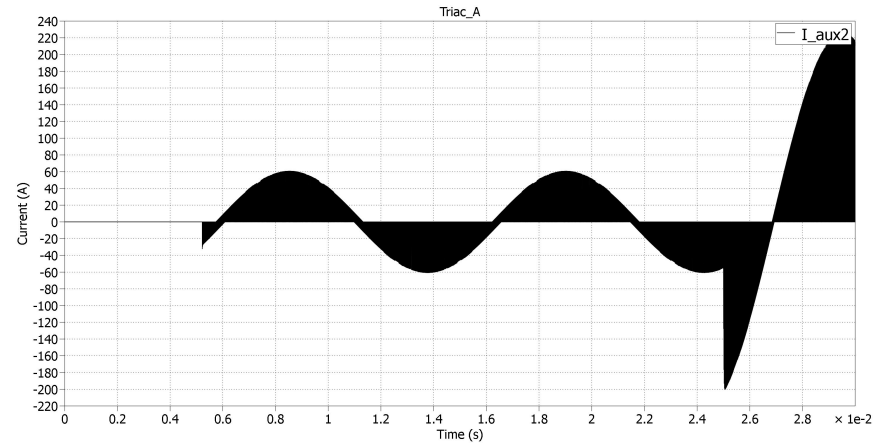

Fig. 11. Current waveform conducted by a triac

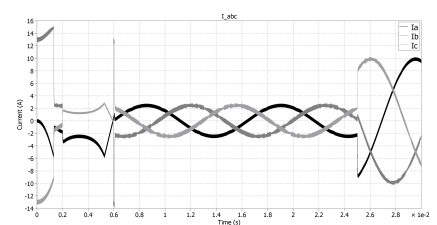

(a) current

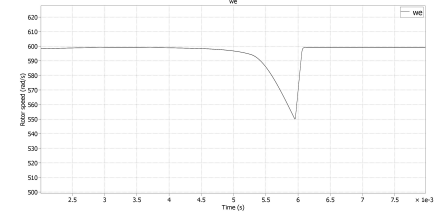

(b) rotor speed
Fig. 12. Phase currents (a) and speed transient (b) when the fault is simulated at $t=2 m s$

simulation of the power-electronic switch failure at Leg 2 is also carried out, and shown in Fig. 13-15. Currents in phase $\mathrm{B}$ and $\mathrm{C}$ overlap in this case of failure, which is shown in Fig. 13. Although the fault clearance time is longer than in the previous simulation, the fault-tolerant operation is thoroughly activated at $t=6 \mathrm{~ms}$, and the output currents remain sinusoidal waveforms after the redundant leg is triggered.

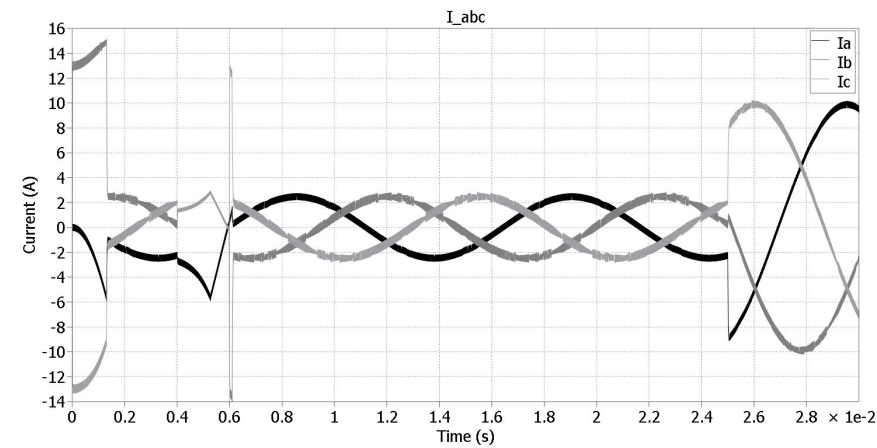

Fig. 13. Three-phase measured currents when a fault occurs at Leg 2, $t_{\text {fault }}=4 \mathrm{~ms}$

Therefore, the performance of the electric drive is maintained by the presented topology and the proposed faulttolerant-control in both case of faults: either open-circuit switch at Leg $1\left(Q_{1}, Q_{2}\right)$ or open-circuit switch at Leg 2 $\left(Q_{3}, Q_{4}\right)$. 


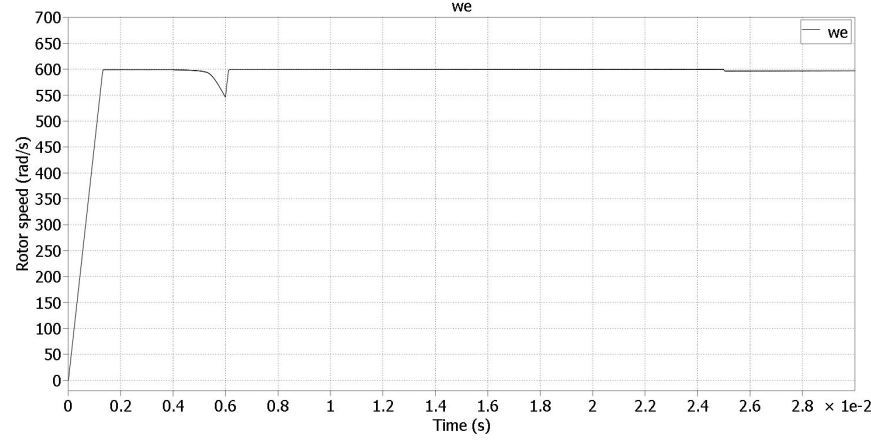

Fig. 14. Mechanical rotor speed of the traction motor when a fault occurs at Leg $2, t_{\text {fault }}=4 \mathrm{~ms}$

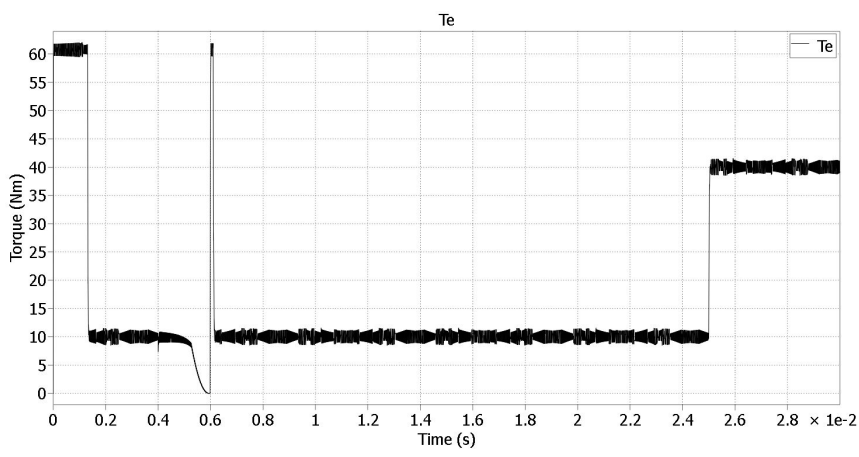

Fig. 15. Corresponding electrical torque in case of a Leg 2 failure

\section{CONCLUSION}

In this paper, a topology consisting of a Scott transformer and a power-electronic converter are presented. Next, a methodology of fault detection for the proposed electrical drive is developed and demonstrated. Finally, a simulation is implemented to verify the topology.

The high-frequency Scott transformer gives several advantages for the fault-tolerant operation of power converters. First, a smaller number of electronic switches is required to achieve three-phase output currents and one power leg in an IPM is thus available as a redundant component for fault-tolerant operation. Second, the connection topology of the Scott transformer is helpful to derive two phase control signals form a three phase current-feedback. Third, a zero-sequence current is an indicator of a fault and it is easily sensed by Hall current sensor.

The simulation presented in the paper shows that the proposed model is able to sustain the operating performance of the power converter in fault-tolerant mode. The architecture proposed for a coupling between a Scott transformer and such diagnosis is suitable for use in conjunction with the faultdetection algorithm. This proposed solution is quite feasible to implement in affordable and approachable hardware, while the increase of physical volume is limited.

In terms of design and platform, this paper proposed a solution to enhance the reliability and the compactness of an electric drive implemented in a PHEVs or EVs. Subsequently, there will be less space required in the automobiles for the power converters, and a reduced over-all weight, compared to other fault-tolerance approaches. Furthermore, a resonantswitching approach is able to increase the switching frequency; hence, the size of Scott transformer is reduced and the efficiency of the converter increases.

The development and adaptation of fault-tolerant systems is essential for a sustainable operation of PHEVs and EVs during traffic circulation. This solution gives a redundancy of power electronic switches in a normal state, by using only two of three legs in an integrated Power switching module and coupling a Scott transformer. The electric current waveforms, motor speed and torque are maintained after clearing fault.

\section{ACKNOWLEDGMENT}

This work is financially supported by VITO - Vlaamse Instelling voor Technologisch Onderzoek, and the Flemish Government of Belgium. This paper is a part of the research "Intelligent Controller of Power Converters for the Large-scale Integration of Renewables Sources into Smart grids", which is funded by Flemish government strategy visions.

\section{REFERENCES}

[1] S. Khwan-on, L. Lillo, L. Empringham, P. Wheeler, C. Gerada, N. M. Othman, O. Jasim, and J. Clare, "Fault tolerant power converter topologies for PMSM drives in aerospace applications," in 13th European Conference on Power Electronics and Applications EPE '09, Barcelona, Spain, 8-10 Sept 2009, pp. 1-9.

[2] C.Cecati, F.Genduso, R.Miceli, and G.R.Galluzzo, "A suitable control technique for fault-tolerant converters in distributed generation," in IEEE International Symposium on Industrial Electronics (ISIE), Gdansk, June 2011, pp. 107 - 112.

[3] R. de Araujo Ribeiro, C. Jacobina, E. da Silva, and A. Lima, "Faulttolerant voltage fed PWM inverter ac motor drives," in IEEE Transactions on Industrial Electronics, vol. Vol. 51, N. 2, April 2004, pp. 439-446.

[4] S. Dwari and L. Parsa, "An optimum control technique for multiphase pm machines under open-circuit faults," in IEEE Transactions on Industrial Electronics, vol. Vol. 55, N.5, May 2008, pp. 1988-1995.

[5] R. Kianinezhad, B. Nahid-Mobarakeh, L. Baghli, F. Betin, and G.Capolino, "Modeling and control of six-phase symmetrical induction machine under fault condition dur to open phases," in IEEE Transactions on Industrial Electronics, vol. Vol. 55, N.5, May 2008, pp. 1966-1977.

[6] F. Genduso and R. Miceli, "A general mathematical model for nonredundant fault-tolerant inverters," in IEEE International Electric Machines and Drives Conference (IEMDC), Niagara Falls, USA, May 2011, pp. 705-710.

[7] T. Park and T. Kim, "Novel fault tolerant power conversion system for hybrid electric vehicles," in IEEE Vehicle Power and Propulsion Conference (VPPC), Chicago, IL, USA, Sept 2011, pp. 1-6.

[8] V. Pires, J. Martins, and C. Hao, "A modular multilevel power converter system for photovoltaic applications," in International Conference on Energy and Electrical Drives (POWERENG), May 2011, pp. 1-5.

[9] V. Pires, M. Guerreiro, J. Martins, and J. Silva, "Three-phase multilevel inverter based on leblanc transformer," in 7th International ConferenceWorkshop on Compatibility and Power Electronics (CPE), vol. 150-154, June 2011.

[10] C. L. C. J. S. Hsu, C. W. Ayers, R. H. Wiles, S. L. Campbell, K. T. Lowe, and R. T. Michelhaugh, "Report on toyota/prius motor torque capability, torque property, no-load back emf, and mechanical losses," Oak Ridge National Laboratory, US, Tech. Rep., 2004.

[11] F. Genduso, R. Miceli, and G. Galluzzo, "Flexible power converters for the fault tolerant operation of micro-grids," in International Conference on Electrical Machines (ICEM), 2010 XIX, Sept 2010, pp. 529-551.

[12] A. Gaillard, S. Karimi, P. Poure, S. Saadate, and E. Gholipour, "A fault tolerant converter topology for wind energy conversion system with doubly fed induction generator," in European Conference on Power Electronics and Applications, 2007, pp. 1-6. 